\title{
METODE SERVQUAL, KUADRAN IPA, DAN INDEKS PGCV UNTUK MENGANALISIS KUALITAS PELAYANAN RUMAH SAKIT X
}

\author{
Ulfi Nur Alifah ${ }^{1}$, Agus Rusgiyono², Alan Prahutama ${ }^{3}$ \\ ${ }^{1}$ Mahasiswa Departemen Statistika, Fakultas Sains dan Matematika, Universitas Diponegoro \\ ${ }^{2,3}$ Staf Pengajar Departemen Statistika, Fakultas Sains dan Matematika, Universitas Diponegoro \\ Email : ulfinuralifah29@gmail.com
}

\begin{abstract}
The quality of service provided by the hospital is very important because it can be used as a reference in determining customer satisfaction. Service quality can be perceived as good and successful if the customer is satisfied with the services and suitable with what customers expect. However, if the services are not suitable with customer expectations, the service quality will be perceived as bad. This study aims to analyze the service quality of X Hospital based on five dimensions of service quality. The data was collected by distributing questionnaires to 64 selected respondents who were patients from Hospital $X$. Then, the data were calculated the value of the gap between customer expectations and perceptions. Then analyzed using the Importance Performance Analysis method and the Potential Gain Customer Value Index to determine the priority of service quality improvement. Based on the research results, there are only 5 indicators that have a positive gap score, which means that the service quality is suitable with customer expectations. From the Importance Performance Analysis quadrant, the indicators of service quality are spread across four quadrants. From the PGCV index, the indicator of service quality that becomes the first priority for improvement is the ease of access to purchase necessities for patients.
\end{abstract}

Keywords : Service Quality, Importance Performance Analysis, Potential Gain Customer Value Index.

\section{PENDAHULUAN}

Pada era modern sekarang ini, kualitas pelayanan yang disediakan rumah sakit menjadi sangat penting karena akan dapat dijadikan salah satu acuan dalam menentukan kepuasan pelanggan rumah sakit. Pihak rumah sakit akan berlombalomba untuk menyediakan layanan dengan kualitas yang terbaik. Kualitas pelayanan yang diberikan oleh pihak rumah sakit akan dapat dipersepsikan baik dan sukses jika pelanggan merasa puas atas layanan yang diberikan dan sesuai dengan apa yang pelanggan ekspektasikan. Namun jika pelayanan yang disediakan rumah sakit tidak sesuai dengan ekspektasi pelanggan, maka kualitas pelayanan akan dipersepsikan buruk.

Salah satu metode populer yang digunakan untuk menganalisis kualitas pelayanan adalah metode SERVQUAL (Service Quality). Dengan metode ini akan didapatkan besaran gap atau kesenjangan antara kinerja rumah sakit dengan apa yang diekspektasikan oleh pelanggan. Penelitian tentang metode SERVQUAL ini pertama kali dilakukan oleh [6] yang menghasilkan lima identifikasi gap atau kesenjangan antara persepsi pihak manajemen dan persepsi pelanggan. Selain SERVQUAL, kualitas pelayanan juga dapat dianalisis menggunakan Kuadran IPA (Importance Performance Analysis). 
Dalam penelitian oleh [4], metode ini membagi indikator kualitas pelayanan kedalam empat kuadran dengan kriteria tertentu. Untuk mengetahui prioritas layanan yang perlu untuk diperbaiki dapat menggunakan Indeks PGCV (Potential Gain Customer Value).

\section{Analisis Kesenjangan Kualitas Pelayanan Model SERVQUAL (Service Quality)}

Model SERVQUAL dikenal pula dengan istilah Gap Analysis Model. Menurut [6] terdapat lima kesenjangan atau gap yang menyebabkan tidak tersampaikannya jasa dengan baik, yaitu:

a. Gap antara harapan pelanggan dan persepsi manajemen (knowledge gap)

b. Gap antara persepsi amanjemen terhadap harapan konsumen dan spesifikasi kualitas jasa (standards gap)

c. Gap antara spesifikasi kualitas jasa dan penyampaian jasa (delivery gap)

d. Gap antara penyampaian jasa dan komunikasi eksternal (communications gap)

e. Gap antara jasa yang dipersepsikan dan jasa yang diharapkan (service gap).

Secara lebih rinci, model konseptual SERVQUAL yang dikemukakan [6] dapat dilihat pada Gambar 1.

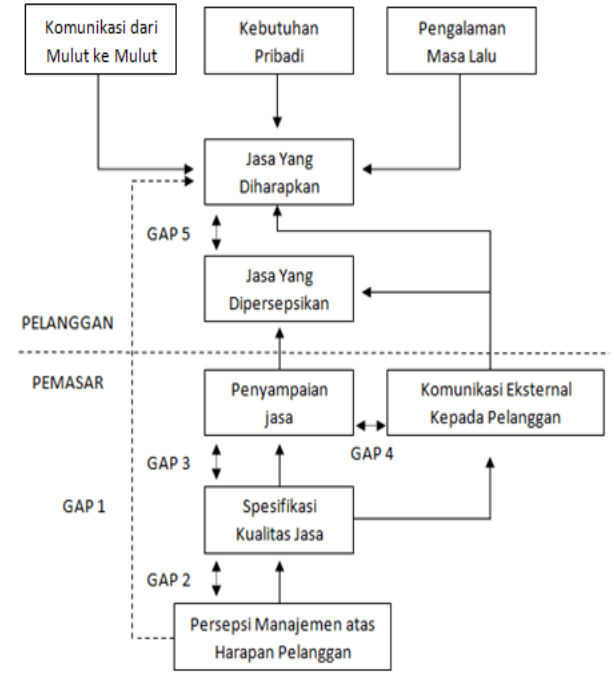

Gambar 1. Model Konseptual SERVQUAL
Dimensi Kualitas Pelayanan Jasa Model SERVQUAL

Terdapat lima dimensi dalam menentukan kualitas pelayanan jasa menurut [7], yaitu:

a. Reliabilitas (reliability): berkaitan dengan kemampuan rumah sakit untuk memberikan layanan yang akurat sejak pertama kali tanpa membuat kesalahan apapun dan menyampaikan jasanya sesuai dengan waktu yang disepakati.

b. Daya Tanggap (responsiveness): berkaitan dengan kesediaan dan kemampuan para karyawan untuk membantu para pelanggan dan merespons permintaan mereka, serta menginformasikan kapan jasa akan diberikan dan kemudian memberikan jasa secara cepat.

c. Jaminan (assurance): berkaitan dengan perilaku para karyawan agar mampu menumbuhkan kepercayaan pelanggan terhadap perusahaan dan perusahaan bisa menciptakan rasa aman bagi para pelanggannya.

d. Empati (emphaty): berkaitan dengan upaya pihak rumah sakit memahami masalah para pelanggannya dan bertindak demi kepentingan pelanggan, serta memberikan perhatian personal kepada para pelanggan dan memiliki jam operasi yang nyaman.

e. Bukti Fisik (tangibles): berkenaan dengan daya tarik fasilitas fisik, perlengkapan, dan material yang digunakan rumah sakit, serta penampilan karyawan.

\section{Pengukuran SERVQUAL}

Model SERVQUAL (kualitas pelayanan) menganalisis gap antara dua variabel pokok, yakni jasa yang diharapkan (expected service) dan jasa yang dipersepsikan (perseived service. Menurut Parasuraman et al. (1990) dalam [9], skor SERVQUAL untuk setiap pasang pernyataan dapat dihitung dengan rumus: 
Skor Kualitas Pelayanan $($ SERVQUAL $)=$ Skor Persepsi - Skor Harapan

\section{Importance Performance Analysis (IPA)}

Dalam metode IPA, nilai rata-rata tingkat kepentingan atribut dan kinerja perusahaan akan dianalisis di ImportancePerformance Matrix yang terdiri dari empat kuadran dengan kriteria tertentu.

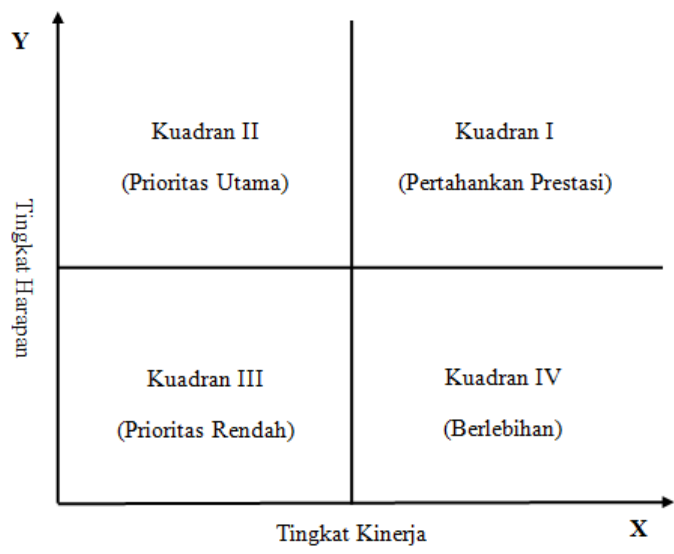

Gambar 2. Kuadran Importance-Performance Matrix

Penjelasan atas masing-masing kuadran di atas menurut [4] adalah sebagai berikut:

a. Kuadran I (pertahankan prestasi/ keep up with the good work)

Menunjukkan bahwa atribut yang berada dalam kuadran ini patut untuk dipertahankan atas kinerja yang telah dicapai. Atribut yang ada pada kuadran ini juga dianggap penting dan diharapkan sebagai faktor penunjang bagi kepuasan pelanggan atau konsumen.

b. Kuadran II (prioritas utama/ concentrate here)

Menunjukkan bahwa atribut yang berada dalam kuadran ini di rasa penting dan diharapkan oleh pelanggan atau konsumen tetapi kinerja rumah sakit dianggap belum memuaskan. Sehingga pihak rumah sakit sebagai penyedia jasa harus memprioritaskan untuk meningkatkan kinerja pada atribut-atribut yang berada pada kuadran ini.

c. Kuadran III (prioritas rendah/ low priority)
Menunjukkan bahwa kinerja yang ditunjukkan oleh rumah sakit rendah atas atribut yang ada, pelanggan atau konsumen juga menganggap atribut kurang penting atau tidak terlalu dibutuhkan sehingga pihak rumah sakit tidak perlu memprioritaskan atribut pada kuadran ini.

d. Kuadran IV (berlebihan/ possible overkill)

Menunjukkan bahwa kinerja yang dihasilkan rumah sakit dianggap terlalu berlebihan, padahal atribut yang ada dalam kuadran ini dianggap kurang terlalu penting oleh pelanggan atau konsumen. Pihak rumah sakit lebih baik mengalokasikan tenaga lebih pada atribut-atribut yang lebih penting dan harus diprioritaskan.

Potential Gain Customer Value (PGCV)

Metode PGCV dapat digunakan untuk menentukan atribut-atribut kualitas pelayanan yang perlu ditingkatkan dan diprioritaskan agar meningkatkan kepuasan bagi pelanggan. Prioritas dalam meningkatkan kualitas pelayanan atas atribut-atribut yang diukur dilihat berdasarkan besarnya nilai indeks PGCV. Atribut dengan nilai indeks PGCV terbesar menjadi prioritas pertama dalam perbaikan dan seterusnya hingga atribut dengan nilai indekss PGCV terkecil. Menurut [2], langkah-langkah menghitung besarnya indeks PGCV adalah sebagai berikut:

1. Menghitung nilai ACV (Achieved Customer Value) dengan rumus:

$$
\mathrm{ACV}=\mathrm{I} \times \mathrm{P}
$$

dengan I: Skor rata-rata ekspektasi atau harapan

P: Skor rata-rata realita atau fakta

2. Menghitung nilai UDCV (Ultimately Desired Customer Value) dengan rumus:

$$
\mathrm{UDCV}=\mathrm{I} \times \text { Pmax }
$$

dengan I: Skor rata-rata ekspektasi atau harapan 
Pmax: Skor maksimum dari pengisian skala Likert kuesioner untuk fakta

3. Menghitung nilai PGCV dengan rumus:

$$
\mathrm{PGCV}=\mathrm{UDCV}-\mathrm{ACV}
$$

\section{Validitas Instrumen}

Menurut [1], sebuah instrumen dikatakan valid jika mampu mengukur apa yang diinginkan. Validitas instrumen ditentukan dengan mengkorelasikan antara skor yang diperoleh setiap butir pertanyaan atau pernyataan dengan skor total dari semua pertanyaan atau pernyataan yang mewakili suatu variabel dimensi. Jika skor tiap butir pertanyaan berkorelasi secara signifikan dengan skor total pada tingkat alfa tertentu maka dapat dikatakan bahwa alat pengukur itu valid. Validitas yang diperoleh dengan cara di atas dikenal dengan validitas isi (content validity) dengan teknik pengerjaan menggunakan analisis butir.

Rumus yang digunakan untuk mencari nilai korelasi pada penelitian ini adalah korelasi Rank Spearman karena data pada penelitian ini merupakan data berskala ordinal yang merupakan urutan/ perankingan.

$$
r_{s}=1-\frac{6 \sum d_{i}^{2}}{n^{3}-n}
$$

dengan $\quad r_{s}$ : koefisien korelasi Rank Spearman

$$
d_{i}^{2}: \text { kuadrat dari selisih }
$$
pasangan peringkat ke-i

$n$ : ukuran sampel (responden)

Selanjutnya, nilai $r_{s}$ dibandingkan dengan nilai $r_{\text {tabel }(\alpha, n)}$. Jika nilai $r_{s}>r_{\text {tabel }(\alpha, n)}$, maka butir pernyataan dianggap valid.

\section{Reliabilitas Instrumen}

Menurut [1], Reliabilitas menunjuk pada suatu pengertian bahwa suatu instrumen cukup dapat dipercaya untuk digunakan sebagai alat pengumpul data karena instrumen tersebut sudah baik. Dalam pengujiannya digunakan teknik
Cronbach's Alpha $\left(\alpha_{c}\right)$. Koefisien reliabilitas Cronbach's Alpha dirumuskan sebagai berikut :

Cronbach'sAlpha $\left(\alpha_{c}\right)$

$$
=\left(\frac{k}{k-1}\right)\left(1-\frac{\sum_{i=1}^{n} \sigma_{i}^{2}}{\sigma_{t}^{2}}\right)
$$

dengan $\quad \alpha_{c}:$ Koefisien reliabilitas instrumen (Cronbach's Alpha)

$k$ : Banyaknya variabel indikator

$\sum \sigma_{i}^{2}$ : Jumlah varian skor tiap variabel indikator

$\sigma_{t}^{2} \quad$ : Varian total

Menurut [5] tinggi rendahnya reliabilitas ditunjukkan oleh suatu angka yang disebut koefisien reliabilitas. Koefisien minimal sebuah alat ukur adalah 0,60, karena sudah dapat menunjukkan suatu hubungan yang cukup kuat.

\section{METODOLOGI PENELITIAN}

\section{Sumber Data dan Variabel Penelitian}

Jenis data yang digunakan untuk penelitian ini adalah data primer yang didapatkan langsung dari jawaban hasil kuesioner yang diberikan kepada responden yaitu konsumen/ pelanggan Rumah Sakit X, lebih tepatnya adalah keluarga dari pasien instalasi rawat inap Rumah Sakit $\mathrm{X}$ yang sedang menjalani perawatan pada bulan Februari-Maret 2020 dan dirawat sekurang-kurangnya $2 \times 24$ jam. Responden yang didapatkan sebanyak 64 responden. Untuk analisis data dilakukan dengan menggunakan bantuan software R.

Variabel penelitian yang digunakan dalam kuesioner untuk mengetahui tingkat kesenjangan kualitas pelayanan Rumah Sakit $\mathrm{X}$ merupakan variabel pelayanan rumah sakit, yang menggunakan 5 dimensi pengukuran terhadap variabel kualitas pelayanan rumah sakit yaitu sebagai berikut:

a. Dimensi Bukti Fisik (tangibles), yang terdiri dari 5 indikator yaitu: 
1. Gedung dan bangunan rumah sakit $\left(\mathrm{X}_{1}\right)$

2. Ketersediaan fasilitas kesehatan $\left(\mathrm{X}_{2}\right)$

3. Ketersediaan fasilitas penunjang lain $\left(\mathrm{X}_{3}\right)$

4. Kenyamanan dan kebersihan ruangan rumah sakit $\left(\mathrm{X}_{4}\right)$

5. Ketersediaan lahan parkir $\left(\mathrm{X}_{5}\right)$

b. Dimensi Kehandalan (reliability), yang terdiri dari 4 indikator yaitu:

1. Pelayanan bidang administrasi $\left(\mathrm{X}_{6}\right)$

2. Kemampuan komunikasi dokter, perawat, dan petugas lainnya $\left(\mathrm{X}_{7}\right)$

3. Tanggung jawab dokter, perawat, dan petugas lainnya $\left(\mathrm{X}_{8}\right)$

4. Obat dan makanan untuk pasien $\left(\mathrm{X}_{9}\right)$

c. Dimensi Daya Tanggap (responsiveness), yang terdiri dari 6 indikator yaitu:

1. Ketepatan waktu pelayanan dokter $\left(\mathrm{X}_{10}\right)$

2. Ketepatan waktu pelayanan bidang administrasi $\left(\mathrm{X}_{11}\right)$

3. Kecekatan dan kedisiplinan saat menangani pasien $\left(\mathrm{X}_{12}\right)$

4. Kesigapan mengatasi komplain $\left(\mathrm{X}_{13}\right)$

5. Kemudahan akses transportasi di sekitar rumah sakit $\left(\mathrm{X}_{14}\right)$

6. Kemudahan akses untuk membeli keperluan bagi pasien $\left(\mathrm{X}_{15}\right)$

d. Dimensi Jaminan (assurance), yang terdiri dari 4 indikator yaitu:

1. Keamanan lingkungan $\left(\mathrm{X}_{16}\right)$

2. Biaya pelayanan yang jelas $\left(\mathrm{X}_{17}\right)$

3. Pengetahuan dokter, perawat, dan petugas lainnya terhadap fasilitas rumah sakit $\left(\mathrm{X}_{18}\right)$

4. Keramahan dan kesopanan pegawai $\left(\mathrm{X}_{19}\right)$ e. Dimensi Empati (emphaty), yang terdiri dari 3 indikator yaitu :

1. Keadilan pelayanan kesehatan $\left(\mathrm{X}_{20}\right)$

2. Kemudahan untuk menghubungi dokter, perawat, atau pihak rumah sakit $\left(\mathrm{X}_{21}\right)$

3. Usaha dalam memahami kebutuhan pasien/ konsumen $\left(\mathrm{X}_{22}\right)$

\section{Langkah-langkah Penelitian}

1. Melakukan Uji Validitas instrumen.

2. Melakukan Uji Reliabilitas instrumen.

3. Melakukan rekapitulasi terhadap semua data yang telah didapatkan dari semua hasil pengisian kuesioner oleh reponden pada software Ms. Excel.

4. Melakukan perhitungan skor kualitas pelayanan (SERVQUAL) untuk masing-masing variabel indikator dari data nilai harapan dan fakta hasil pengisian kuesioner untuk mengetahui nilai gap/ kesenjangan antara harapan dan fakta.

5. Melakukan perhitungan Importance Performance Analysis (IPA) dari data nilai harapan dan fakta hasil pengisian kuesioner untuk kemudian disajikan dalam Importance-Performance Matrix.

6. Melakukan perhitungan Indeks Potential Gain Customer Value (PGCV) dari data nilai harapan dan fakta hasil pengisian kuesioner untuk mengetahui atribut yang harus diprioritaskan peningkatan kualitas pelayanannya.

\section{ANALISIS DAN PEMBAHASAN Uji Validitas Instrumen}

Berdasarkan hasil output $\mathrm{R}$, nilai $r_{s}$ dari semua indikator $>r_{\text {tabel }(0,05 ; 30)}(0,362)$ maka semua indikator sebagai item pernyataan dianggap valid, yang berarti 
item pernyataan yang digunakan sebagai instrumen pengukuran kualitas pelayanan Rumah Sakit X dapat mengukur apa yang ingin diukur.

\section{Uji Reliabilitas Instrumen}

Berdasarkan output R, diketahui bahwa nilai koefisien Cronbach's Alpha pada dimensi tangibles, reliability, responsiveness, assurance, dan emphaty lebih dari 0,60. Sehingga dapat disimpulkan bahwa indikator kualitas pelayanan sebagai pernyataan pada dimensi pelayanan yang diberikan kepada responden adalah reliabel atau konsisten.

\section{Analisis Gap Kualitas Pelayanan (SERVQUAL/ Service Quality)}

Berikut ini hasil perhitungan nilai gap atau skor SERVQUAL.

Tabel 1. Perhitungan Skor SERVQUAL

\begin{tabular}{|c|c|c|c|c|}
\hline Dimensi & Indikator & $\begin{array}{c}\text { Skor } \\
\text { Harapan }\end{array}$ & $\begin{array}{c}\text { Skor } \\
\text { Fakta } \\
\end{array}$ & Gap \\
\hline \multirow{5}{*}{ Tangibles } & $\mathrm{X}_{1}$ & 4,1406 & 4,0938 & $-0,0469$ \\
\hline & $\mathrm{X}_{2}$ & 4,1875 & 4,2188 & 0,0313 \\
\hline & $\mathrm{X}_{3}$ & 4,2656 & 2,9688 & $-1,2969$ \\
\hline & $\mathrm{X}_{4}$ & 4,3906 & 4,1719 & $-0,2188$ \\
\hline & $\mathrm{X}_{5}$ & 3,9063 & 4,0313 & 0,1250 \\
\hline \multirow{4}{*}{ Reliability } & $\mathrm{X}_{6}$ & 4,0000 & 4,0156 & 0,0156 \\
\hline & $X_{7}$ & 4,0625 & 4,1563 & 0,0938 \\
\hline & $\mathrm{X}_{8}$ & 4,5156 & 4,2188 & $-0,2969$ \\
\hline & $\mathrm{X}_{9}$ & 4,6250 & 4,1563 & $-0,4688$ \\
\hline \multirow{6}{*}{$\begin{array}{l}\text { Responsivene } \\
\text { ss }\end{array}$} & $\mathrm{X}_{10}$ & 4,4375 & 3,9219 & $-0,5156$ \\
\hline & $\mathrm{X}_{11}$ & 4,1094 & 3,9375 & $-0,1719$ \\
\hline & $\mathrm{X}_{12}$ & 4,5313 & 4,0938 & $-0,4375$ \\
\hline & $X_{13}$ & 4,4063 & 4,0156 & $-0,3906$ \\
\hline & $\mathrm{X}_{14}$ & 4,2813 & 3,2344 & $-1,0469$ \\
\hline & $\mathrm{X}_{15}$ & 4,2813 & 2,6094 & $-1,6719$ \\
\hline \multirow{4}{*}{ Assurance } & $\mathrm{X}_{16}$ & 4,0469 & 4,2188 & 0,1719 \\
\hline & $\mathrm{X}_{17}$ & 4,1250 & 3,9375 & $-0,1875$ \\
\hline & $\mathrm{X}_{18}$ & 4,3594 & 4,1094 & $-0,2500$ \\
\hline & $\mathrm{X}_{19}$ & 4,5938 & 4,1719 & $-0,4219$ \\
\hline \multirow{3}{*}{ Emphaty } & $\mathrm{X}_{20}$ & 4,2969 & 4,1406 & $-0,1563$ \\
\hline & $\mathrm{X}_{21}$ & 4,2031 & 4,1563 & $-0,0469$ \\
\hline & $X_{22}$ & 3,9531 & 3,8594 & $-0,0938$ \\
\hline
\end{tabular}

Berdasarkan Tabel 1 di atas, hanya terdapat lima indikator yang memiliki gap positif yaitu $\mathrm{X}_{2}$ (ketersediaan fasilitas kesehatan), $\mathrm{X}_{5}$ (ketersediaan lahan parkir), $\mathrm{X}_{6}$ (pelayanan bidang administrasi), $\mathrm{X}_{7}$ (kemampuan komunikasi dokter, perawat, dan petugas lainnya), dan $\mathrm{X}_{16}$ (keamanan lingkungan), yang artinya kualitas pelayanan yang dirasakan oleh pelanggan terhadap lima indikator tersebut sesuai dengan yang diharapkan oleh pelanggan. Sedangkan indikator sisanya memiliki gap negatif yang artinya kualitas pelayanan yang dirasakan oleh pelanggan tidak sesuai atau lebih buruk dari yang diharapkan oleh pelanggan.

\section{Kuadran IPA}

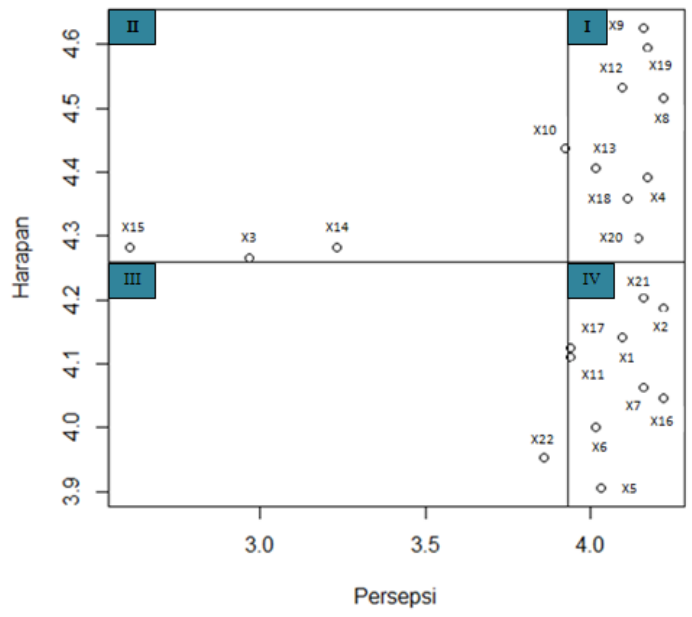

Gambar 3. Importance-Performance Matrix

Persebaran indikator-indikator kualitas pelayanan di atas adalah sebagai berikut:

a. Kuadran I, menunjukkan tingkat harapan atau ekspektasi pelanggan tinggi begitu pula dengan tingkat fakta atau persepsi (kinerja rumah sakit). Ini berarti bahwa indikator yang berada pada kuadran ini dianggap penting oleh pelanggan. Rumah Sakit X sebagai penyedia jasa juga telah memberikan pelayanan yang baik pada indikator-indikator tersebut sehingga pelanggan dapat diasumsikan puas. Oleh karena itu, pihak Rumah Sakit X harus mempertahankan kinerja dan kualitas pelayanannya pada indikator- 
indikator di kuadran ini yaitu $\mathrm{X}_{4}$ (kenyamanan dan kebersihan ruangan rumah sakit), $\mathrm{X}_{8}$ (tanggung jawab dokter, perawat, dan petugas lainnya), $\mathrm{X}_{9}$ (obat dan makanan untuk pasien), $\mathrm{X}_{12}$ (kecekatan dan kedisiplinan saat menangani pasien), $\mathrm{X}_{13}$ (kesigapan mengatasi komplain), $\quad \mathrm{X}_{18}$ (pengetahuan dokter, perawat, dan petugas lainnya terhadap fasilitas rumah sakit), $\mathrm{X}_{19}$ (keramahan dan kesopanan pegawai), dan $\mathrm{X}_{20}$ (keadilan pelayanan kesehatan).

b. Kuadran II, menunjukkan tingkat harapan atau ekspektasi pelanggan tinggi namun tingkat fakta atau persepsi (kineja rumah sakit) rendah. Ini berarti bahwa indikator yang berada pada kuadran ini dianggap penting oleh pelanggan namun pelayanan yang diberikan oleh Rumah Sakit X sebagai penyedia jasa dirasa masih kurang sehingga pelanggan merasa kurang puas. Hal ini menjadi evaluasi tersendiri bagi pihak Rumah Sakit X untuk harus meningkatkan lagi kualitas pelayanannya pada indikator yang terdapat pada kuadran ini yaitu $\mathrm{X}_{3}$ (ketersediaan fasilitas penunjang lain), $X_{10}$ (ketepatan waktu pelayanan dokter), $\mathrm{X}_{14}$ (kemudahan akses transportasi di sekitar rumah sakit), dan $\mathrm{X}_{15}$ (kemudahan akses untuk membeli keperluan bagi pasien).

c. Kuadran III, menunjukkan tingkat harapan atau ekspektasi pelanggan rendah begitu pula dengan tingkat fakta atau persepsi (kinerja rumah sakit). Ini dapat diartikan bahwa indikator yang berada pada kuadran ini dianggap tidak terlalu penting sehingga belum dirasa perlu dan pelanggan tidak terlalu mempermasalahkan rendahnya kinerja penyedia jasa. Indikator yang terdapat pada kuadran ini adalah $\mathrm{X}_{22}$ (usaha dalam memahami kebutuhan pasien/ konsumen).

d. Kuadran IV, menunjukkan tingkat harapan atau ekspektasi pelanggan rendah namun tingkat fakta atau persepsi (kinerja rumah sakit) tinggi. Ini dapat diartikan bahwa indikator yang berada pada kuadran ini dianggap belum dirasa perlu oleh pelanggan sehingga tidak perlu terlalu diprioritaskan, namun kinerja penyedia jasa dianggap berlebihan. Indikator yang berada pada kuadran ini adalah $\mathrm{X}_{1}$ (gedung dan bangunan rumah sakit), $\mathrm{X}_{2}$ (ketersediaan fasilitas kesehatan), $\mathrm{X}_{5}$ (ketersediaan lahan parkir), $\mathrm{X}_{6}$ (pelayanan bidang administrasi), $\quad \mathrm{X}_{7} \quad$ (kemampuan komunikasi dokter, perawat, dan petugas lainnya), $\mathrm{X}_{11}$ (ketepatan waktu pelayanan bidang administrasi), $\mathrm{X}_{16} \quad$ (keamanan lingkungan), $\mathrm{X}_{17}$ (biaya pelayanan yang jelas), dan $\mathrm{X}_{21}$ (kemudahan untuk menghubungi dokter, perawat, atau pihak rumah sakit).

\section{Analisis Indeks PGCV (Potential Gain Customer Value)}

Indeks PGCV digunakan untuk menentukan skala prioritas atas indikatorindikator pelayanan yang harus ditingkatkan dan diperbaiki.

Indikator dengan nilai indeks PGCV terbesar adalah $\mathrm{X}_{15}$ yaitu "kemudahan akses untuk membeli keperluan bagi pasien" dengan nilai indeks PGCV sebesar 10,2349. Sehingga indikator $X_{15}$ ini menempati ranking pertama sebagai prioritas utama peningkatan kualitas pelayanan oleh Rumah Sakit X sebagai penyedia jasa. Sedangkan indikator dengan nilai indeks PGCV terkecil adalah $\mathrm{X}_{16}$ yaitu "keamanan lingkungan". 
Tabel 2. Perhitungan Nilai Indeks PGCV

\begin{tabular}{c|c|c|c|l}
\hline Indikator & $\mathrm{ACV}$ & $\mathrm{UDCV}$ & $\mathrm{PGCV}$ & $\begin{array}{l}\text { Ranking } \\
\text { Prioritas } \\
\text { Perbaikan }\end{array}$ \\
\hline $\mathrm{X}_{1}$ & 16,9507 & 20,7031 & 3,7524 & 15 \\
$\mathrm{X}_{2}$ & 17,6660 & 20,9375 & 3,2715 & 21 \\
$\mathrm{X}_{3}$ & 12,6636 & 21,3281 & 8,6646 & 2 \\
$\mathrm{X}_{4}$ & 18,3171 & 21,9531 & 3,6360 & 17 \\
$\mathrm{X}_{5}$ & 15,7471 & 19,5313 & 3,7842 & 14 \\
$\mathrm{X}_{6}$ & 16,0625 & 20,0000 & 3,9375 & 10 \\
$\mathrm{X}_{7}$ & 16,8848 & 20,3125 & 3,4277 & 20 \\
$\mathrm{X}_{8}$ & 19,0503 & 22,5781 & 3,5278 & 19 \\
$\mathrm{X}_{9}$ & 19,2227 & 23,1250 & 3,9023 & 11 \\
$\mathrm{X}_{10}$ & 17,4033 & 22,1875 & 4,7842 & 4 \\
$\mathrm{X}_{11}$ & 16,1807 & 20,5469 & 4,3662 & 7 \\
$\mathrm{X}_{12}$ & 18,5498 & 22,6563 & 4,1064 & 9 \\
$\mathrm{X}_{13}$ & 17,6938 & 22,0313 & 4,3374 & 8 \\
$\mathrm{X}_{14}$ & 13,8472 & 21,4063 & 7,5591 & 3 \\
$\mathrm{X}_{15}$ & 11,1714 & 21,4063 & 10,2349 & 1 \\
$\mathrm{X}_{16}$ & 17,0728 & 20,2344 & 3,1616 & 22 \\
$\mathrm{X}_{17}$ & 16,2422 & 20,6250 & 4,3828 & 6 \\
$\mathrm{X}_{18}$ & 17,9143 & 21,7969 & 3,8826 & 12 \\
$\mathrm{X}_{19}$ & 19,1646 & 22,9688 & 3,8042 & 13 \\
$\mathrm{X}_{20}$ & 17,7917 & 21,4844 & 3,6926 & 16 \\
$\mathrm{X}_{21}$ & 17,4692 & 21,0156 & 3,5464 & 18 \\
$\mathrm{X}_{22}$ & 15,2566 & 19,7656 & 4,5090 & 5 \\
\hline & \multicolumn{5}{|l}{}
\end{tabular}

\section{KESIMPULAN}

Berdasarkan hasil dan pembahasan yang telah dilakukan, maka kesimpulan yang dapat diambil adalah dari 22 indikator pelayanan, hanya terdapat 5 indikator dengan nilai gap positif, yang artinya kualitas pada indikator-indikator pelayanan tersebut telah sesuai dengan apa yang pelanggan harapkan atau ekspektasikan, sedangkan 17 indikator yang lain tidak sesuai dengan apa yang pelanggan ekspektasikan. Berdasarkan analisis kuadran Importance-Performance Matrix menunjukkan bahwa indikatorindikator pelayanan menyebar di empat kuadran. Dari 22 indikator terdapat 4 indikator yang seharusnya menjadi prioritas utama manajemen rumah sakit karena berada pada kuadran II, yang menunjukkan bahwa indikator-indikator pada kuadran tersebut dianggap penting oleh pelanggan namun kinerja pihak rumah sakit justru rendah dan tidak sesuai. Dari analisis indeks PGCV diketahui bahwa prioritas pertama manajemen rumah sakit jika ingin memperbaiki kualitas pelayananannya adalah indikator "kemudahan akses membeli keperluan bagi pasien", sedangkan prioritas terakhir adalah indikator "keamanan lingkungan rumah sakit".

\section{DAFTAR PUSTAKA}

[1] Arikunto, S. 2010. Prosedur Penelitian. Jakarta: Rineka Cipta.

[2] Hom, W. C. 1997. Make Customer Service Analysis a Little Easier With the PGCV Index. Quality Progress, 89-93.

[3] Kotler, P., \& Keller, K. L. 2016. Marketing Management. 15th Edition. United States: Pearson Education.

[4] Martilla, J. A., \& James, J. A. 1977. Importance-Performance Analysis. Journal of Marketing Vol. 41, No. 1, 77 - 79.

[5] Murti, B. 2011. Validitas dan Reliabilitas Pengukuran. Jurnal Fakultas Kedokteran, Mei 2011.

[6] Parasuraman, A., Zeithaml, V. A., \& Berry, L. L. 1985. A Conceptual Model of Service Quality and Its Implications for Future Research. Journal of Marketing Vol. 49, Fall, $41-50$.

[7] Parasuraman, A., Zeithaml, V. A., \& Berry, L. L. 1988. SERVQUAL: A Multiple-Item Scale for Measuring Consumer Perceptions of Service Quality. Journal of Retailing Vol. 64, No.1, 12 - 40.

[8] Tjiptono, F., \& Chandra, G. 2007. Service, Quality \& Satisfaction. Edisi ke-2. Yogyakarta: CV Andi Offset.

[9] Tjiptono, F., Chandra, Y., \& Diana, A. 2004. Marketing Scales. Yogyakarta: CV Andi Offset.

[10] UPT Rumah Sakit X. 2020. Profil Rumah Sakit X. (http://Rumah Sakit X.undip.ac.id/profil/). Di akses pada tanggal 23 Februari 2020. 